\title{
STUDIES OF TOTAL PULMONARY CAPACITY AND ITS SUB- DIVISIONS. III. CHANGES WITH BODY POSTURE
}

\author{
By ALBERTO HURTADO ${ }^{1}$ and WALTER W. FRAY \\ (From the Department of Medicine of the School of Medicine and Dentistry of the \\ Unie'ersity of Rochester and the Medical Clinic and Dizision of Radiology \\ of the Strong Memorial and Rochester Municipal Hospitals, \\ Rochester, Now York)
}

(Received for publication April 7, 1933)

It has been known for many years that the posture of the body has an influence on pulmonary capacity. More than 25 years ago Bohr (3) and Plesch (10) found that the residual air increases in the recumbent position. Christie and Beams (6) in 1922 observed a reduction of 5.5 per cent in the vital capacity in the latter position, and Wilson (11) a few years later, demonstrated that this is brought about by a marked reduction in the reserve air. Binger and Brow (2) in 1924 found a considerable decrease in the functional residual air (mid capacity) with subjects flat in bed. The average reduction in nine cases was 0.80 liters. In recent years Anthony (1) reported practically no change in the volume of residual air depending on different positions of the body, but confirmed the previous finding that there is marked reduction in the reserve air in the recumbent position, and pointed out that the volume of complementary air changes in the opposite direction; it increases on assuming this position. Calhoun, Cullen and Harrison et al. (5) in 1931 found similar influences due to the position of the body on the pulmonary capacity.

We have shown in a previous paper (8) that there is a definite correlation between the total capacity and its subdivisions and the size of the chest cavity. It will be interesting, therefore, to discover whether changes in position are also accompanied by similar and proportional alterations in size and expansion of the chest. Hamilton and Morgan (7), in a recent communication, reported that in five normal subjects there was no change in the volume of residual air in the recumbent position, but they observed a moderate decrease in the vital capacity, and consequently a corresponding diminution in the total capacity when lying was compared with the sitting posture. These investigators, measuring the lateral and anteroposterior diameters of the chest, found a moderate increase when the suljects were recumbent, but failed to find consistent changes in the level of the diaphragm. From their observations they concluded that the chest cavity was larger when the body is recumbent and that the reduction in total volume

${ }^{1}$ Travelling Fellow of the Rockefeller Foundation. 
and vital capacity in this posture possibly is brought about by accumulation of blood in the pulmonary circuit.

There is evidence in the literature to show that when recumbent there is diminution in the size of the cavity of the chest. Briscoe (4), from careful observations, concluded that in this position there is a considerable reduction, and that this is affected chiefly by an elevation of the diaphragm, while the lateral and anteroposterior diameters of the chest show very slight increase. Livingstone (9) in 1928 reported that in normal indivicluals the capacity of the chest is least in the supine posture, and that this corresponds with a higher level of the diaphragm and with practically no change in the diameters of the thorax.

To stucly this matter. further, we have made observations of 10 healthy males (average age 23 years) regarding the influence of posture on the capacity of the lungs and the size and expansion of the chest. The determinations of pulmonary capacity in the sitting and recumbent positions were made with a few minutes' interval. Radiographs of the chest were obtained at maximum and at normal expiration and inspiration. The methods and technique employed in these observations, and the different measurements obtained from the radiographs, have already been described (8).

\section{CHANGES IN PULMONARY CAPACITY WITH BODY POSTURE}

The variations found (Table I) are interesting and, in general, agree with the work of previous investigators. When subjects assume the recumbent position there is, as compared with the sitting posture, a moderate reduction in the total capacity, vital capacity, and residual air (the average diminutions are 9.0, 6.6, and 14.5 per cent respectively), with more marked changes in the reserve air and mid capacity (28.2 and 41.7 per cent). The only volume which shows an alteration in the opposite direction is the complementary air. Its increase (11.1 per cent) is, however, proportionally lower than the decrease in the reserve air, so that the vital capacity is nevertheless reduced.

In the course of our investigation we also determined the vital capacity of 32 healthy males in the erect and lying positions. The results of these observations closely agree with the corresponding changes found in the ten cases. The average vital capacity in the erect posture was 5.06 liters, while in the lying position it was 4.77 liters, a difference of 0.29 liters, a reduction of 5.7 per cent.

The alterations in the absolute values of some of the subdivisions, on assuming the recumbent posture, are of course reflected in their relative values, because the total volume is proportionally less altered. There are very slight changes in the ratios: (Vital capacity/Total volume) and (Residual air/Total volume), but on the other hand, there are marked reductions in the ratios of reserve air and mid capacity to the total volume. 
TABLE I

Changes in pulmonary capacity according to posture (mean of 10 observations)

\begin{tabular}{|c|c|c|c|c|}
\hline \multirow{2}{*}{ Determinations } & \multicolumn{2}{|c|}{ Means } & \multirow{2}{*}{\multicolumn{2}{|c|}{ Variation }} \\
\hline & Sitting & Lying & & \\
\hline 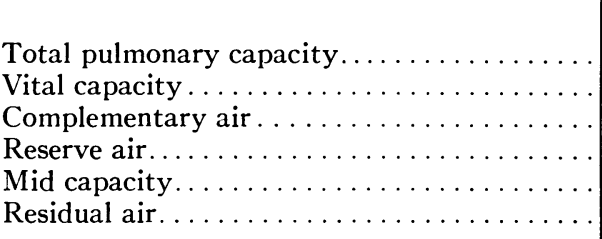 & $\begin{array}{l}\text { liters } \\
6.64 \pm 0.18 \\
4.99 \pm 0.12 \\
3.32 \pm 0.10 \\
1.68 \pm 0.07 \\
3.33 \pm 0.14 \\
1.65 \pm 0.10\end{array}$ & $\begin{array}{l}\text { liters } \\
6.04 \pm 0.19 * \\
4.66 \pm 0.14 \\
3.69 \pm 0.12 \\
0.98 \pm 0.06 \\
2.39 \pm 0.11 \\
1.41 \pm 0.09\end{array}$ & $\begin{array}{r}\text { percent } \\
-9.0 \\
-6.6 \\
+11.1 \\
-41.7 \\
-28.2 \\
-14.5\end{array}$ & $\begin{array}{l}\text { liters } \\
0.60 \\
0.33 \\
0.37 \\
0.70 \\
0.94 \\
0.24\end{array}$ \\
\hline Ratios & per cent & per cent & & \\
\hline 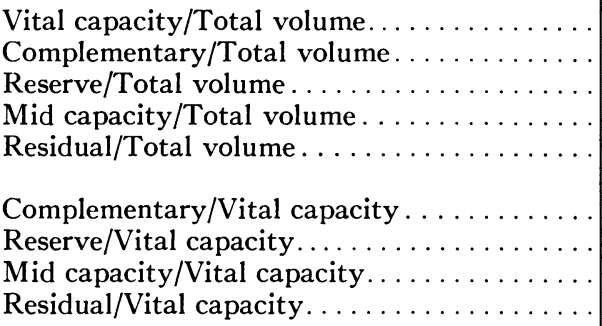 & $\begin{array}{l}75.4 \pm 1.17 \\
49.6 \pm 1.15 \\
25.3 \pm 0.83 \\
49.9 \pm 1.15 \\
24.5 \pm 1.06 \\
64.8 \pm 1.95 \\
33.5 \pm 1.06 \\
66.7 \pm 2.47 \\
33.1 \pm 2.05\end{array}$ & $\begin{array}{l}76.9 \pm 1.01 \\
60.8 \pm 0.96 \\
16.2 \pm 0.96 \\
39.2 \pm 0.95 \\
23.0 \pm 1.13 \\
78.8 \pm 1.19 \\
21.0 \pm 1.12 \\
51.3 \pm 1.78 \\
30.4 \pm 1.85\end{array}$ & $\begin{array}{r}+1.9 \\
+22.5 \\
-35.9 \\
-21.4 \\
-6.1 \\
+21.5 \\
-37.3 \\
-23.0 \\
-8.1\end{array}$ & \\
\hline
\end{tabular}

* Probable error.

The complementary air increases and therefore its ratio is increased. The complementary air makes up a bigger part of the vital capacity and the reserve air, the other component, is correspondingly reduced.

The changes just mentioned in the absolute and relative values of the pulmonary capacity and its subdivisions, according to posture, indicate the necessity of making all determinations under similar and standard conditions to permit proper comparison. This fact has often been overlooked in the past.

\section{INFLUENCE OF POSTURE ON SIZE AND EXPANSION OF THE CHEST}

The different measurements obtained from the radiological films taken in the sitting and recumbent postures, are summarized in Table II. Considering first the changes occurring in the size of the chest, it will be noted that when recumbent the level of the diaphragm is distinctly higher, and that this is more marked at mid capacity (after a normal expiration). It is also higher at maximum expiration and inspiration but to a much smaller degree. The actual measurements of the height of the right and left sides of the diaphragm show that at mid capacity they are 5.6 and $4.1 \mathrm{~cm}$. higher than in the sitting position. The higher level attained is slightly more marked in the right diaphragm. 


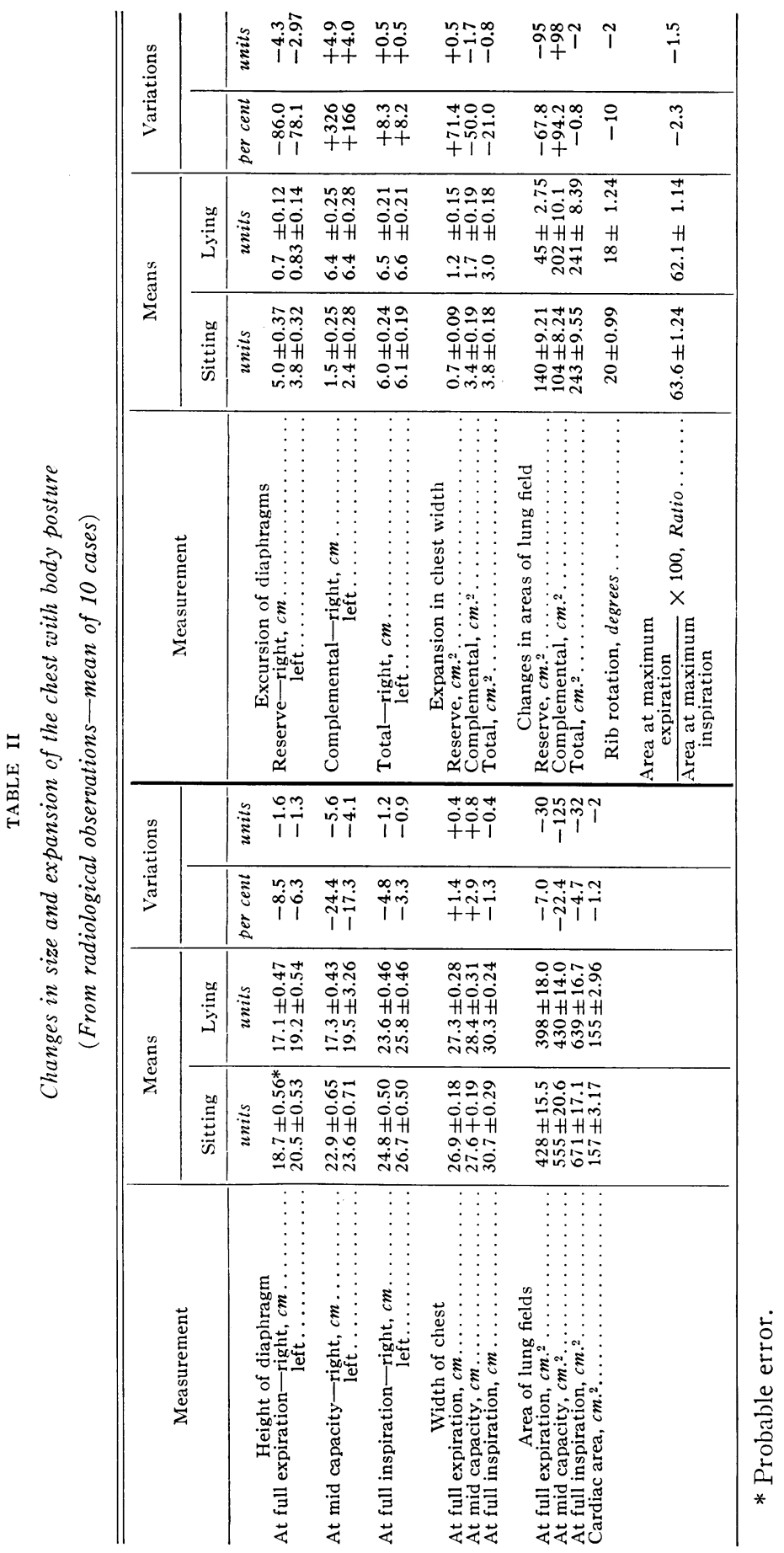


It is interesting to see that the lateral diameter of the chest shows a very slight change, less than one centimeter, when the posture is varied from sitting to recumbency. We have not measured the anteroposterior diameter, but from other investigations already cited, it probably shows no change.

The size of the areas of lung fields shows similar alterations. At mid capacity it is reduced 22.4 per cent. At maximum expiration and inspiration the areas are slightly smaller, although the decrease is only 7.0 and 4.7 per cent respectively.

From these observations it appears that the alterations in the size of the chest are of similar character to the variations in pulmonary capacity. We have seen that the volume of mid capacity is most markedly reduced (as compared with the total volume and residual air) and that similar alteration occurs in the radiological area of the lungs at this respiratory position. We have found that the decrease in pulmonary capacity is somewhat more marked, however, than the changes in the radiological area of the lungs. The total volume is reduced 9.0 per cent, while the area at full inspiration is only 7.0 per cent smaller. The mid capacity decreases 28.2 per cent, while the corresponding area shows a reduction of 22.4 per cent, and finally the residual air decreases 14.5 per cent and the area at maximum expiration has diminished only 4.7 per cent in size. Does this mean that part of the alveolar space is encroached upon by the increased size of the capillary bed? This explanation may be correct, as has often been suggested, but it is worth emphasizing that we have not found a marked discrepancy between the changes in pulmonary capacity and chest size.

Comparison of the expansion of the chest in the sitting and recumbent positions is interesting. We will consider first the diaphragmatic excursion. While recumbent there is a very slight increase in the maximum excursion but the difference is less than a centimeter. The movement of the diaphragm during the determination of the reserve air is much decreased. This is evident on both sides, although slightly more on the right. While sitting, the "reserve" excursion of the right diaphragm is $5.0 \mathrm{~cm}$. and of the left $3.0 \mathrm{~cm}$., and it decreases to 0.7 and 1.0 respectively in recumbency. On the other hand, the "complemental" diaphragmatic excursion (during a forced inspiration starting from the mid capacity) shows a very striking increase in recumbency.

The measurements of the areas of the lungs on a radiograph at different respiratory positions (at maximum expiration and inspiration, and after a normal expiration and inspiration) indicate the changes in the size of these areas during the determination of the several subdivisions of the total volume (vital capacity, reserve air, complementary and tidal air). By comparing these differences in area in the sitting and recumbent positions we find that in the latter posture there is relatively a small variation in 
the areas, corresponding to the vital capacity and ticlal air, while there is considerable diminution in the area corresponding to the reserve air, and a marked increase in the area corresponding to the complementary air.

The alterations alrealy demonstrated in certain of the pulmonary capacity sublivisions. When the recumbent position is adopted, are accompanied loy sinilar and parallel changes in chest expansion. It thus appears that the increase in complementary air and the decrease in the reserve air are related to corresponding variations in the degree of chest expansion.

In recumbency there is a slight reduction in the radio: (Area at maximum expiration Area at maximum inspiration $) \times 100$, although the difference is very small.

The relation of posture to corresponding changes in pulmonary capacity and size and expansion of the chest, as inclicated by the areas of the projection of the lungss, may be clearly appreciated from a study of figure 1.

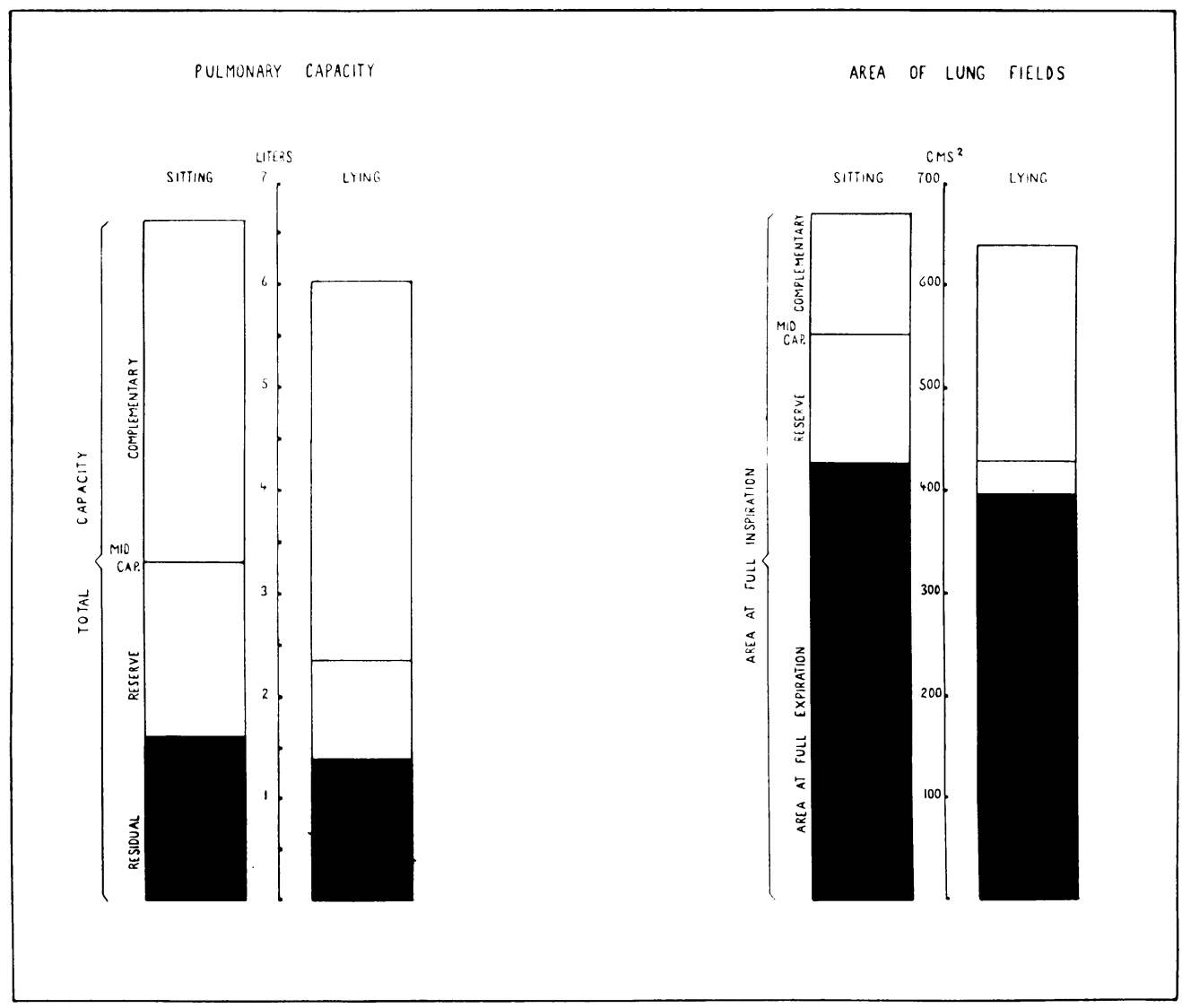

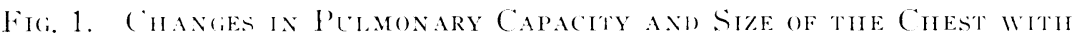
l'OSTLRE (AVRRACES FROM 10 ORSERVATONS) 
The effects of posture upon pulmonary capacity and the size and expansion of the chest have been observed in 10 healthy males by comparing measurements made in the recumbent and sitting postures.

It has been found that when recumbent there are slight decreases in the total volume, the vital capacity, and the residual air, but the reserve air decreases markedly. On the other hand, there is a marked increase in the volume of the complementary air.

Similar and parallel decreases, although proportionally less marked have been demonstrated to occur in the size of the chest. This diminution is most marked at mid capacity and it is caused by an upward displacement of the diaphragm.

An analysis of the expansion of the chest in both sitting and recumbent positions shows also parallel changes. In the latter posture, the diaphragmatic excursion and the change in the area of the projection of the iungs corresponding to the reserve air are considerably reduced, while the reverse is true in relation to the complementary air.

These observations furnish additional data regarding the close correlation existing between the pulmonary capacity and the size and expansion of the chest and indicate the necessity for adopting a standard posture when investigations of this nature are made.

\section{BIBLIOGRAPHY}

1. Anthony, A. J., Deutsches Arch. f. klin. Med., 1930, clxvii, 129. Untersuchungen über Lungenvolumina und Lungenventilation.

2. Binger, C. A. L., and Brow, G. R., J. Exper. Med., 1924, xxxix, 677. Stuclies on the Respiratory Mechanism of Lobar Pneumonia. A Study of Lung Volume in Relation to the Clinical Course of the Disease.

3. Bohr, C., Deutsches Arch. f. klin. Med., 1907, 1xxxviii, 385. Die funktionellen Änderungen in der Mittellage und Vitalkapazität der Lungen.

4. Briscoe, J. C., Quart. J. Med., 1919-20, xiii, 293. The Mechanism of Postoperative Massive Collapse of the Lungs.

Idem, Lancet, 1931, ii, 513. The Mechanism of Inflation of the Lungs.

5. Calhoun, A., Cullen, G. E., Harrison, T. R., Wilkins, W. L., and Tims, M. M., J. Clin. Invest., 1931, x, 833. Studies in Congestive Heart Failure. XIV. Orthopnea: Its Relation to Ventilation, Vital Capacity, Oxygen Saturation and Acid-base Condition of Arterial and Jugular Blood.

6. Christie, C. D., and Beams, A. J., Arch. Int. Med., 1922, xxx, 34. The Estimation of Normal Vital Capacity, with Especial Reference to the Effect of Posture.

7. Hamilton, W. F., and Morgan, A. B., Am. J. Physiol., 1931-32, xcix, 526. Mechanism of the Postural Reduction in Vital Capacity in Relation to Orthopnea and Storage of Blood in the Lungs.

S. Hurtado, A., and Fray, W. W., J. Clin. Invest., 1933, xii, . Studies of Total Pulmonary Capacity and Its Subdivisions. II. Correlation with Physical and Radiological Measurements. 
9. Livingstone, J. L., Lancet, 1928, i, 754. Variations in the Volume of the Chest with Changes in Posture.

10. Plesch, C., Ztschr. f. exper. Path. u. Therap., 1913, xiii, 165. Die pathologische Physiologie des Lungenvolumens und seine Beziehung zum Kreislauf.

11. Wilson, W. H., J. Physiol., 1927-28, 1xiv, 54. The Influence of Posture on the Volume of the Reserve Air. 